\title{
Edukasi Kesehatan Reproduksi Remaja Di Karangtaruna Pendowohardjo
}

\author{
${ }^{1}$ Pri Hastuti*, ${ }^{2}$ Desi Ekawati \\ ${ }^{1}$ Kebidanan, STIKES AKBIDYO Yogyakarta \\ ${ }^{2}$ Kesehatan Masyarakat, STIKES AKBIDYO Yogyakarta \\ *Email: prihas2018@gmail.com
}

\begin{abstract}
Adolescence is the initial period of maturity of the reproductive organs in humans or the so-called puberty. Based on previous preliminary studies, adolescents prefer sources of reproductive health information obtained from peers and parents, but if this is not given an explanation from health workers directly it will cause different perceptions from each teenager which can cause gaps. Based on the preliminary study, researchers are interested in doing community service with the title "Adolescent Reproductive Health Education in Karangtaruna Pendowohardjo". The purpose of this research is to increase the knowledge of adolescents about the importance of reproductive health from a physical and psychological perspective. Adolescent Reproductive Health Education Activities at Karangtaruna Pendowohardjo were carried out using counseling and demonstration methods, the media used using teaching aids. The target audience in this community service is Youth, especially Youth Organizations in Pendowohardjo Sewon Bantul with a target number of 48 Youth Youth Organizations. The results of this research are that adolescents gain knowledge and skills regarding Reproductive Health through counseling and demonstrations.
\end{abstract}

Keywords: Adolescence, Reproductive health education, Counseling, Adolescent reproductive health

\begin{abstract}
Abstrak
Masa remaja adalah masa awal kematangan organ reproduksi pada manusia atau yang disebut masa pubertas. Berdasarkan studi pendahuluan sebelumnya remaja lebih menyukai sumber informasi kesehatan reproduksi diperoleh dengan teman sebaya dan orangtua, namun apabila hal ini tidak diberikan penjelasan dari tenaga kesehatan langsung akan menimbulkan persepsi yang berbeda-beda dari masing - masing remaja yang dapat menimbulkan kesengjangan. Berdasarkan studi pendahuluan, peneliti tertarik untuk melakukan pengabdian masyarakat dengan judul "Edukasi Kesehatan Reproduksi Remaja di Karangtaruna Pendowohardjo". Tujuan dilakukannya penelitian ini adalah Meningkatkan pengetahuan remaja tentang pentingnya kesehatan reproduksi dari segi fisik dan psikologisnya. Kegiatan Edukasi Kesehatan Reproduksi Remaja di Karangtaruna Pendowohardjo dilaksanakan dengan metode penyuluhan dan demonstrasi, media yang digunakan menggunakan alat peraga. Khalayak sasaran dalam pengabdian masyarakat ini adalah Remaja khususnya Karangtaruna di Pendowohardjo Sewon Bantul dengan jumlah sasaran adalah 48 remaja Karangtaruna. Hasil penelitian remaja mendapatkan pengetahuan dan keterampilan mengenai Kesehatan Reproduksi melalui penyuluhan dan demonstrasi.
\end{abstract}

Kata Kunci:Masa Remaja,Edukasi Kesehatan Reproduksi,Penyuluhan,Kesehatan Reproduksi Remaja 


\section{PENDAHULUAN}

Masa remaja adalah masa transisi dari anak-anak menuju dewasa, yang dimasuki pada usia 10 hingga 12 tahun. Masa remaja disebut juga dengan masa pubertas. Menurut BKKBN, program kesehatan reproduksi remaja adalah untuk membantu remaja agar memiliki pengetahuan, kesadaran, sikap dan perilaku hidup reproduksi sehat bertanggungjawab, melalui advokasi, promosi, KIE, konseling dan pelayanan kepada remaja yang memiliki permasalahan khusus. Materi kesehatan reproduksi remaja mencakup aspek kehidupan remaja yang terkait dengan pengetahuan, sikap dan perilaku kehidupan seksual serta berkeluarga. Di Jawa Tengah pada tahun 2010 khususnya pada Kota semarang, tingkat pengetahuan kesehatan reproduksi menunjukan 43,2\% memeliki pengetahuan rendah, 37, $2 \%$ memiliki pengetahuan cukup dan 19,5 memeiliki pengetahuan yang baik (PKBI, 2010). Berdasarkan studi pendahuluan sebelumnya remaja lebih menyukai sumber informasi kesehatan reproduksi diperoleh dengan teman sebaya dan orangtua, namun apabila hal ini tidak diberikan penjelasan dari tenaga kesehatan langsung akan menimbulkan persepsi yang berbeda-beda dari masing - masing remaja yang dapat menimbulkan kesengjangan. Berdasarkan studi pendahuluan, peneliti tertarik untuk melakukan pengabdian masyarakat dengan judul "Edukasi Kesehatan Reproduksi Remaja di Karangtaruna Pendowohardjo" dengan tujuan penelitian mampu melakukan edukasi tentang kesehatan reproduksi pada remaja di Karangtaruna Pendowohardjo, Guna meningkatkan pengetahuan remaja tentang pentingnya kesehatan reproduksi, dari segi fisik dan psikologisnya melalui edukasi kesehatan tentang reproduksi.

\section{METODE}

a. Metode Kegiatan

Kegiatan Edukasi Kesehatan Reproduksi Remaja di Karangtaruna Pendowohardjo dilaksanakan dengan metode penyuluhan dan demonstrasi, media yang digunakan menggunakan alat peraga. Rinciaan pelaksanaan kegiatan ini adalah sebagai berikut:

1. Pembukaan dengan memberikan pengarahan kegiatan yang akan dilakukan

2. Pendataan peserta

3. Penyuluhan tentang Kesehatan Reproduksi Remaja selanjutnya dilakukan demonstrasi tentang Teknik Personal Hyigine yang benar dengan bantuan alat peraga dan mahasiswa

4. Diskusi dan tanya jawab

5. Pemberian hadiah hadir

6. Menyampaikan kesimpulan

7. Penutup

\section{b. Khalayak Sasaran}

Khalayak sasaran dalam pengabdian masyarakat ini adalah Remaja khususnya Karangtaruna di Pendowohardjo Sewon Bantul. Sasaran ini dinilai cukup berpotensi mendukung hasil pengabdian masyarakat ini. Jumlah sasaran adalah 48 remaja Karangtaruna di Pendowohardjo Sewon Bantul.

\section{c. Tempat Dan Waktu Pelaksanaan}

\section{Tempat Kegiatan}

Kegiatan pengabdian kepada masyarakat tentang Edukasi Kesehatan Reproduksi Remaja di Karangtaruna Pendowohardjo dilaksanakan di Balai Desa Pendowoharjo, Sewon, Bantul.

\section{Waktu Pelaksanaan}

Kegiatan Pengabdian kepada masyarakat tentang Edukasi Kesehatan Reproduksi Remaja di Karangtaruna Pendowohardjo dilaksanakan pada hari Sabtu 3 Juli 2021 pukul 09.00 WIB. 


\section{HASIL DAN PEMBAHASAN}

Kegiatan Edukasi tentang Kesehatan Reproduksi Remaja di laksanakan Hari Sabtu, 3 Juli 2021 pukul 09.00 WIB di Karangtaruna Dusun Pendowohardjo. Remaja mendapatkan pengetahuan dan keterampilan mengenai Kesehatan reproduksi dan Pencegahan penyakit menular akibat seks bebas. Peserta hadir 48 orang, diantaranya sebagian besar berusia 16 sampai dengan 19 tahun. Edukasi dan demonstrasi yang diberikan dengan pendekatan holistik dan komunikasi efektif dan bantuan praktis, sehingga remaja dapat maksimal mendapatkan informasi tentang kesehatan reproduksi guna mendukung remaja dengan pemahaman akan reproduksi yang sehat dan mempersiapkan untuk kehamilannya kelak.

Intervensi sudah diberikan sesuai dengan agenda pelaksanaan dengan kehadiran 48 orang. Kesesuaian agenda diantaranya sebagai berikut:

1. Mengkoordinasikan pelaksanaan kegiatan bersama dengan remaja Karangtaruna Panggunghardjo Sewon dilakukan 2 minggu sebelum kegiatan Persiapan peralatan dan perlengkapan 1 minggu sebelum pelaksanaan

2. Pelaksanaan dilakukan dalam sekali waktu yaitu Hari Sabtu, 3 Juli 2021 pukul 09.00 WIB di Karangtaruna Pendowohardjo Sewon Bantul pukul 09.00 s.d 12.30 wib.

3. Pendokumentasian pelaksanaan kegiatan

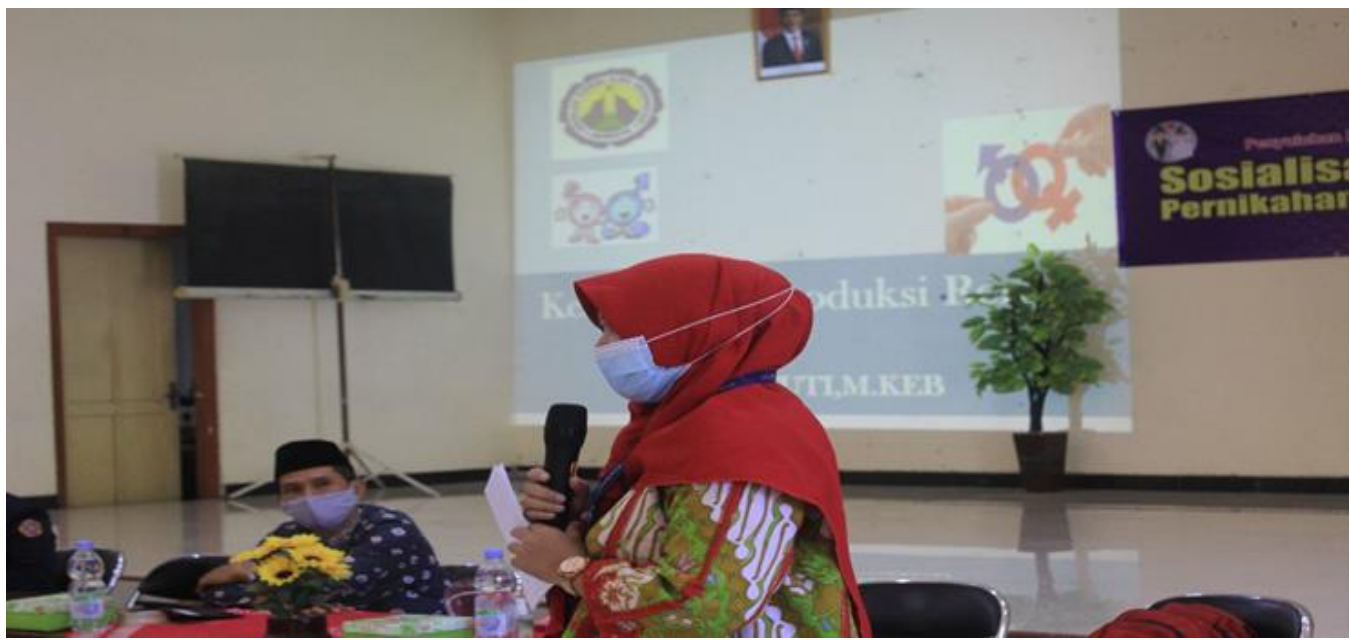

Gambar 1. Pemaparan materi

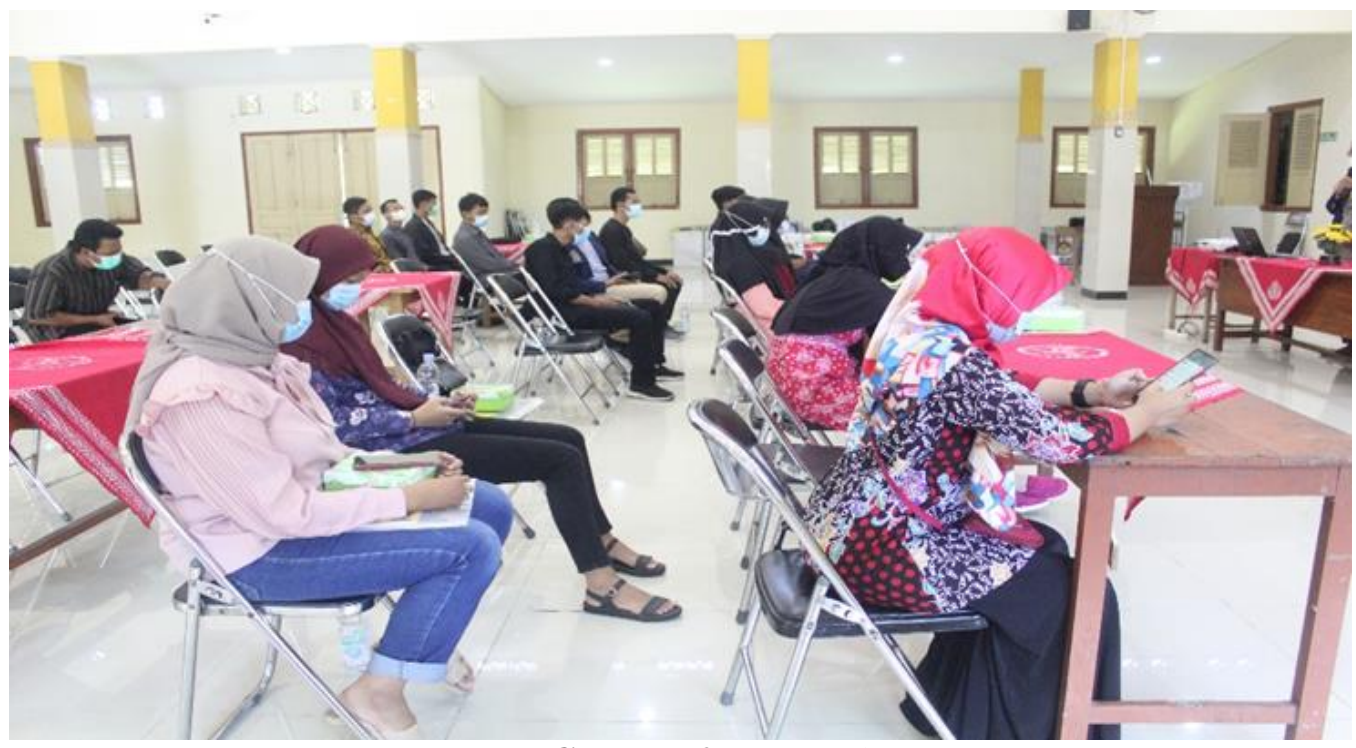

Gambar 2. Responden 
Kendala yang terjadi pada saat kegiatan tidak terdapat kendala yang berarti hanya perlu ditingkatkan beberapa pelaksanaan seperti:

1. Koordinasi dari masing-masing pihak yang terkait ditingkatkan Kembali

2. Memperbanyak kegiatan dalam 1x pengabdian yang berkesinambungan, guna nmenindak lanjuti hasil pengabdian sebelumnya.

3. Memberikan waktu luang baik dari pihak pelaksana maupun pihak sasaran agar tercapainya tujuan dari pelaksanaan pengabdian maksimal.

\section{KESIMPULAN}

Pelaksanaan kegiatan Edukasi tentang kesehatan reproduksi remaja berjalan baik, ditandai dengan kehadiran peserta yaitu 48 orang. Remaja mendapatkan pengetahuan dan keterampilan mengenai Kesehatan Reproduksi melalui penyuluhan dan demonstrasi. Edukasi dan demonstrasi yang diberikan dengan pendekatan holistik dan komunikasi efektif dan bantuan praktis, sehingga remaja dapat maksimal mendapatkan informasi tentang kesehatan reproduksi guna mendukung remaja dengan pemahaman akan reproduksi yang sehat dan mempersiapkan untuk kehamilannya kelak.

\section{DAFTAR PUSTAKA}

Anita. 2010. Kesehatan Reproduksi. Yogyakarta : Fitramaya.

Arsyad, A. (2011). Media Pembelajaran cetakan ke-15.Jakarta : rajawali Pers

Manuba, I.A.C., MAnuba,I.B.G.F., Manuba, I.B.G., 2009. Memahami Kesehatan Reproduksi Wanita.

Jakarta: EGC.

Michael P. O'Donnell (2009) Definition of Health Promotion 2.0: Embracing Passion, Enhancing Motivation, Recognizing Dynamic Balance, and Creating Opportunities.

American Journal of Health Promotion: September/October 2009, Vol. 24, No. 1 Nasria.

Putriani. 2010. Faktor-faktor yang mempengaruhi pengetahuan remaja tentang kesehatan reproduksi di SMA 1 Mojogedang. 8-9.

Notoadmojo, S. 2007. Promosi Kesehatan \& Ilmu Perilaku. Jakarta: Rineka Cipta.

Notoadmojo, S. 2012. Metodologi Penelitian Kesehatan. Jakarta: Rineka Cipta

Nydia, rena. 2012. Pengaruh Penyuluhan terhadap Tingkat Pengetahuan Kesehatan Reproduksi remaja siswa SMP Kristen Gergaji.Jurnal media medika.

Rachmi. 2007. Modul Pelatihan Pelayanan Kesehatan Peduli Remaja. Direktorat Jenderal Bina Kesehatan Masyarakat. Jakarta 